\title{
Measuring Self-Identity Change Related to English Language Learning and Bilingual Education among Chinese-Speaking College Students: An Exploratory Study
}

\author{
Fuhui Tong ${ }^{1}$ \\ Yue Min' \\ Yi-chun Liu ${ }^{3}$ \\ Haitao Guo ${ }^{4}$
}

'Department of Educational Psychology Associate Director, Center for Research and Development in Dual Language and Literacy Acquisition Texas AङM University College Station, TX, USA

Email:fuhuitong@tamu.edu

Department of Educational Psychology Texas AङM University College Station, TX, USA

Email:mavat011@tamu.edu

${ }^{s}$ Department of Applied Foreign Languages Chia Nan University of Pharmacy and Science Taiwan

Email:yichunliu@gmail.com

${ }^{t}$ College of Mass Communication, The Center for Media and Social Changes Shenzhen University Shenzhen, China

Email:tongivy@hotmail.com

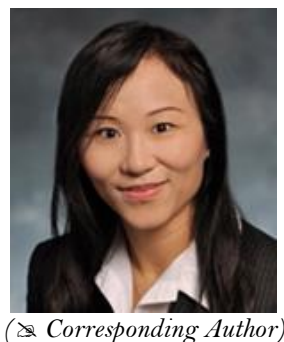

\begin{abstract}
The purpose of this study is two-fold. First, we explored the psychometric properties of a selfidentity change instrument that was previously developed for English learning college students in China. Second, using this instrument, we examined participants' self-identity change related to gender, major, and years of English learning. A total of 273 undergraduate students from two adjacent geographic locations (Taiwan and mainland China) participated in a paper-based survey. Exploratory factor analysis (EFA) revealed five sub-scales that were mainly consistent with the original version. However, the EFA also suggested exclusion of one item, multi-dimensionality, and room for improvement of this instrument regarding item reliability. Inferential statistics revealed that (a) students in Taiwan exhibited a higher self-confidence change as compared to their mainland peers; (b) English and bilingual science majors underwent higher change in additive and subtractive bilingualism, followed by art and humanity majors; (c) for bilingual majors, those who started learning English prior to grade 3 were better able to switch between two identities than those who started in middle school and beyond; and (d) gender is not a significant predictor of identity change. Discussion was contextualized within educational policy and practice regarding English learning and bilingual education in these two locations.
\end{abstract}

Keywords: Self-identity, College students, Chinese-speaking English learners, Exploratory factor analysis.

Citation | Fuhui Tong. Yue Min; Yi-chun Liu; Haitao Guo (2017). Measuring Self-Identity Change Related to English Language Learning and Bilingual Education among Chinese-Speaking College Students: An Exploratory Study. Asian Journal of Education and Training, 3(2): 135-146.

History:

Received: 13 July 2017

Revised: 19 September 2017

Accepted: 12 December 2017

Published: 5 January 2018

Licensed: This work is licensed under a Creative Commons

Attribution 3.0 License $($ (c) $)$ Er

Publisher:Asian Online Journal Publishing Group
Contribution/Acknowledgement: All authors contributed to the conception and design of the study.

Funding: This study received no specific financial support

Competing Interests: The authors declare that they have no conflict of interests.

Transparency: The authors confirm that the manuscript is an honest, accurate, and transparent account of the study was reported; that no vital features of the study have been omitted; and that any discrepancies from the study as planned have been explained.
studures of the study have been omitted

study as planned have been explained.
Ethical: This study follows all ethical practices during writing.

\section{Contents}

1. Introduction

2. Method.

3. Results

4. Discussion..........u. 142








\section{Introduction}

Learning a language is inseparable from the exposure to the culture that is encoded in that language (Risager, 2006; Tong, 2008) and therefore, the learning is not just a process of cognitive activity, but also involves becoming a member of a new cultural and linguistic community and developing multiple identities (Baker, 2011). In the field of second language learning, particularly when the second language is English, research on identity has emerged as a prominent area of interest (Norton, 2006) more evidently in a context where English is not the language of the society (e.g., (Gao et al., 2005;2007; Xu and Gao, 2014)). Counter-arguments have been raised regarding the relevance of studying the change in L2 identity in these contexts as learners have limited opportunities in exposure to the target community $(\mathrm{Qu}, 2005$; Block, 2007). However, the rapidly changing economic, sociocultural, and political development of these regions (such as mainland China and Taiwan, where this current study took place) is associated with the increased international communication where English is regarded as an international language or lingua franca rather than a foreign language (Crystal, 2003; Baker and Wright, 2017). During this process of globalization, in addition to the learning that typically occurs in a closed classroom setting, individuals in developing countries are provided with abundant access to members and internet media to connect to the Englishspeaking world and its cultures that can be integrated into their self-concept of the new cultural identities (Jensen et al., 2011). Further, according to Baker (2011) there is a growing interest of bilingual education in higher education pertaining to multilingual learners' identity, whereas studies in L2 identity are very limited in nonEnglish speaking locations (Gao et al., 2015; Mokhtarnia and Ghafar-Samar, 2016). Given the uprising popularity of bilingual education in these countries that fall into Kachru (1985) categorization of outer circle such as China (Tong and Shi, 2012; Tong and Tang, 2017) Japan (Tsuneyoshi, 2005) South Korea (Park, 2007) and Turkey (Sert, 2008) the topic of self-identity deserves continued attention and exploration because a better and deeper understanding derived from this collection of research can inform policy and practice in English language teaching and bilingual education in a broadened worldwide perspective.

\subsection{Theoretical Framework: A Socio-Psychological Perspective on L2 Self-Identity}

The theoretical framework guiding this research draws from a social psychological view of identity as a static and enduring construct (Lambert, 1974; Gardner, 1985; Dörnyei, 2005). Within the social psychological paradigm, focus has been devoted to individual learner characteristics including linguistic (e.g., bilingual proficiency) and affective outcomes (e.g., attitudes, motivation, identity, and cultural values) that have stable patterns of development (Lasagabaster, 2013; Gao et al., 2015). This group of classical studies related to bilingual education can be represented by 4 bilingual-friendly models: subtractive and additive bilingualism (Lambert, 1974) socio educational model on L2 acquisition (Gardner, 1985) a contemporary view on L2 Motivational Self System (Dörnyei, 2005) and the cognitive-developmental model of social identity integration (CDMSII, Amiot et al. (2007)).

According to Lambert (1974) there are three contributing precursors (i.e., attitudes, aptitude, and motivation) to bilingual proficiency that determine individual learner's self-esteem and self-concept in L2, which is related to two consequences of bilingualism: additive (the maintenance of $\mathrm{L}_{1}$ and native culture with the addition of acquiring target language and culture identity), and subtractive (the replacement of $\mathrm{L}_{1}$ and native culture with the acquisition of target language and culture identity). In Gardner (1985) 4-stage L2 acquisition model, attitudes, motivation, and cultural values are regarded as non-linguistic outcomes, alongside with bilingual proficiency as the linguistic outcome resulted from L2 learning. The proposed two orientations of an individual learner's attitude toward the target culture which is a predictor of the target language proficiency included: instrumental (more popularly identified in outer circles) and integrative motivation. This over-simplistic dichotomy of Gardner's model was reframed by Dörnyei (2005) in his L2 self-motivation system, which stipulated the learning motivation as represented by the desire to find a harmony between who they are (actual self) and what they want to become in the future (ideal self). Such multiple perspectives of self, according to Dörnyei, are appropriate for adolescents or older learners as younger learners might not be able to realize or consider multiple selves. Similarly, Erikson (1968) contended that children formed their primary self-identity at adolescence stage, and a final self-identity was constructed when they grow into adulthood, when self-identity will remain as a relatively stable form onward which leads to established patterns in language learning as a social behavior. Finally, in a similar notion of age that is associated with cognition, the model of social identity integration (CDMSII, (Amiot et al., 2007; Amiot et al., 2015) explains how cultural and social identities change and become integrated in the self. The cognitive development connects an individual's original identity with the new identity as a result of L2 learning, and allows for a simultaneously integration of both cultural identities into a coherence in the self-concept.

Although some other scholars view identity rather as a fluid and complex trait that fluctuates over time as a result of interaction between the learner and the social surroundings (Bosma and Kunnen, 2001; Gao et al., 2015) in this current study, we focus on its role of 'product' rather than 'process' or 'trigger' of learning for the fact that the adult participants in this study have had at least eight years of experiences in English learning, and consequently, have formed a fairly stable and coherent core of self at the time.

\subsection{Operational Definition of Self-Identity Related to Social Identity and Bilingual/L2 Learning}

Self-identity is one of the 50 types of self-concept, according to American Psychological Association Database (PSYCHINFO database), along with self-esteem, self-efficacy, self-awareness, self-respect, etc. However, unlike most self-concept subjects as "I", or "Me", which is highly connected with personal emotion, self-identity responds to external environment, which is strongly connected to the "social role" that is originated from social-identity theory (Ellemers et al., 2002; Dörnyei and Ushioda, 2009). As a result, our definition of self-identity starts from an examination of its intimate relationship with social identity (Tajfel, 1974). More specifically, personal characteristics decide self-identity and group-related self-identity shifts along to social-identity (Terry et al., 1999). Further, it is agreed that an individual's social psychological health and social behavior are closely integrated (Oliver, 2013) and people's self-identity is one of the components that belong to the category of social psychology associated with social behavior (Jiang et al., 2016). A person maintains his or her self-identity from continuously 
contacting the external world, suggesting that self-identity is constructed from individual biographies (Giddens, 1991). In short, the feeling of self-identity is developed from social contact and experiences.

Applying such definition into L2 learning and bilingual education, we assert that second or foreign language learning is linked to social behavior and the development of these languages depends on social interaction across the span from infanthood to adulthood (Johnson and Newport, 1989). People feel relaxed and comfortable when they speak a language that is the same with other people in their social circle, and when they can be understood easily, resulting a sense of belongings. Therefore, the ultimate goal of learning a foreign language is merging into the community of target language (Matsumoto and Obana, 2001) which further supports our claim that L2 selfidentity change derives from the social behavioral experiences of being exposed to the target language and culture, hence, is worth examination, especially given the multilayered self-identities by gender, ethnicity, age, social class, etc. (Baker, 2011).

\subsection{Types of Self-Identity among Bilingual and EFL Learners}

There are many reasons an individual learns a second or third (or even more) language (Gallagher-Brett, 2005) and the most important three include: cultural awareness, cognitive development, and social and emotional development and self-confidence (Baker, 2011). Self-confidence is one reflection of self-identity, defined as an individual's belief in his or her own particular skill (Steele, 1997). In terms of second or foreign language learning, highly confident students hold fewer doubt towards their English abilities, which lowers anxiety towards foreign language speaking (Noels et al., 1996) therefore, self-confidence is the most important determinant on second language learning acquisition (Clément et al., 1994). Self-confidence is also related to an individual's past experiences in L2 learning (Gao et al., 2005). Empirical evidence was reported that Chinese EFL learners' own judgement (self-concept) of their English language abilities was influenced by their performance in English pronunciation (Wang, 2004).

Self-identity can also be represented by Lambert (1974) distinction of additive and subtractive bilingualism, which are closely connected with social adaptation as two diverge aspects of language learning self-identity (Sussman, 2000). As the additive identity is enhanced, there is an integration of the target culture and linguistic identity with the maintenance of the identity of origin; when the subtractive identity elevates, and when people are more involved in the target culture, they feel less connected with their home culture, and therefore, their identity of origin decreases (Noels et al., 1996; De la Sablonnière et al., 2016). It was found that the subtractive pattern of identification takes place when new identity has a higher and legitimate status compared with the original one, highlighting the possible different patterns of identity integration (De la Sablonnière et al., 2016).

Split change is also one type of self-identity; a psychologically depressed mood which is the cognitive reaction to social role (Brewer, 1993). People gain split identity when facing strange culture, language, or lifestyles which are different from their original habits. The split change can be quite intense when there is a violent conflict between the perceived native language and culture and the target language and culture (Mokhtarnia and GhafarSamar, 2016). Commonly, learners who firmly maintain the identity of a target culture tend to suffer more frustration in language learning process compared to learners without such strong identity.

\subsection{Empirical Evidence Related to L2 Self-Identity in EFL Context}

Although the topic of self-identity was not introduced into Asia-based context until about a decade ago, findings from earlier studies highlighted that English learning impacted Chinese-speaking students' cultural orientation (e.g., (Garrott, 1995; Tong, 2008)). More specifically, students in these studies have been reported to accept the norm of target culture and behave accordingly. These findings point to the change in cultural identity, which can be integrated into self-identity. Further, researchers have identified factors that account for the formation and change of self-identity including: gender (Hay and Ashman, 2003; Papacharissi, 2010; Irby et al., 2011) major (Boyd et al., 2003; Boonchum, 2009) and years of formal English learning (Huang et al., 2015; Kai and Shin, 2015).

For example, in Karakitapoglu-Aygün (2004) empirical study with 205 Turkish undergraduate students (average age of 20 years old) on their self-identity, results showed that women are testified more independent and less emotional than men. Hwang (2010) chose gender as moderating variable for predicting self-identity on technology mediated learning. He investigated self-identity level among 211 male undergraduate students and 200 female students from China and discovered that compared to female students, male students achieved higher average score on their self-identity measure.

Empirical results suggest that major should also be included when analyzing learners' self-identity. Gao and associates conducted a series of studies (Gao et al., 2005;2007;2015; Xu and Gao, 2014) among Chinese college students' self-reported identity change as a result of English learning. These studies converged that English majors experienced more self-identity change (both additive and subtractive) than non-English majors. Such difference was intuitively expected, as English majors' competence in English proficiency is indicative of their achievement or success, which intensified their sensitivity toward English (Gao et al., 2015). Using Gao et al. (2005) self-identity instrument, Mokhtarnia and Ghafar-Samar (2016) examined Iranian college students' identity change and their attitudes toward English native speakers. Interestingly, major was not found to be a significant predictor on any type of identity-change. In a similar study, English majors demonstrated more change in split and subtractive identity among Thai college students (Boonchum, 2009).

In addition, the length of language learning is also an important predictor that affects students' self-identity. Boonchum (2009) investigated 113 Thailand undergraduate students who started learning English from different ages, and discovered that language learning self-identity change was dependent of learner's age as well as the age of initial language. More specifically, students with more years of English learning encountered lower change in subtractive identity.

Finally, self-identity, or self-concept in L2 was found to be examined hand in hand with L2 learning motivation (Dörnyei, 2005; Xu and Gao, 2014). For example, Xu and Gao (2014) in their longitudinal study with Chinese EFL learners discovered that cultural (e.g., going abroad) motivation is significantly correlated with subtractive identity 
change, and instrumental (e.g., self-development) motivation is highly associated with self-confidence. According to the authors, there is also a dynamic and reciprocal relationship between motivation and identity, which implicates the importance of self-identity among bilingual and English learners.

\subsection{Summary}

The review of literature reveals a few limitations that lead to the purpose of this study. First, there is a limited number of research on language and identity that is conducted outside an English-speaking environment (Mokhtarnia and Ghafar-Samar, 2016) therefore, the guiding premises that have been proved to be appropriate for Western Anglo-speaking community might not fully represent the nature of identity or identity in L2 scholarship in a context where English is not an everyday language (Norton and Toohey, 2011). Second, in a related vein, instruments that were originally designed for L2 learners in an English-dominant environment (e.g., De la Sablonnière et al. (2016)) would not capture the nature of identity formation and integration that characterizes nonEnglish contexts. Consequently, there is a lack of psychometrically sound instruments available that can facilitate researchers to further explore the field of self-identity as related to L2 and bilingual education. Third, although differences have been reported between student groups such as gender and major, the source of such difference is often times overlooked. Scrutiny of the educational policy and practice that is embodied in social context is essential, which in turn, can inform or refine policy and practice in English language teaching and bilingual education so as to promote students' confidence and identity integration for an additive change. After all, identity change is a product of social interaction. Therefore, the purpose of this current study is two-fold. First, through factor analysis, we test the psychometric properties of a self-identity change instrument that was previously developed for English-learning college students in China. Second, we apply this instrument to examine participants' self-identity change related to gender, major, and starting point of formal English learning in two adjacent geographic locations (i.e., mainland China and Taiwan). More specifically, we seek to answer three research questions:

1. What is the underlying factor structure of the identity change instrument utilized in this study?

2. What is the self-identity change (as reflected by self-confidence, additive bilingualism, and subtractive bilingualism) in Chinese-speaking college students as a result of English language learning or bilingual education? 3. Does the change in self-identity differ by student gender, major, geographic location, and starting point of English learning?

\section{Method}

\subsection{Sampling and Participants}

A convenience sampling strategy was adopted to recruit a total of the 273 undergraduate students, with 193 from a four-year college in Taiwan, and 80 from a tier-I university in mainland China. Among the participants from Taiwan, 98 majored in arts and humanities, 95 majored in English; all 80 undergraduate students from mainland China majored in bio-science, and were taking a bilingual content area course at the time of data collection (see Author 2012 for more information on this bilingual course). These students were in the same year when the data were collected, and there was no statistically significant difference in the age across gender and major, with an average of 21 years old. Their demographic information is described in Table 1. There is a higher percentage of female students in the Taiwan group, which is commensurate with the type of majors (i.e., arts and humanities) that these students chose. Length of English learning is divided into 3 groups based on the educational policy in mainland China and Taiwan that public schools are encouraged to offer mandatory English class from grade 3 and onward (Ministry of Education of the People's Republic of China, 2001; Ministry of Education of Taiwan, 2008). Therefore, in our study, students who started learning English before mid-primary school (i.e., grade 3, hence, 12 years and above) were considered early-exposure, students who started learning English between mid-primary (i.e., grade 3) and beginning of middle school (i.e., grade 6, hence 9-11 years of learning) were considered averageexposure, and learners who started after grade 6 were grouped as late-exposure, with 8 years or less of English learning period. There are about $30 \%$ of early-exposure students in both locations.

Table-1. Breakdown of Participants by Location, Gender, Major, and Years of English Learning

\begin{tabular}{l|l|l|l|l|l|l|l|l}
\hline Location & \multicolumn{3}{|l|}{ Gender } & \multicolumn{3}{l}{ Major } & \multicolumn{3}{l}{ Starting grade (years) of formal English learning } \\
\hline & Male & Female & Arts & English & Science & $\begin{array}{l}\text { before grade } 3(\geq \\
12 \text { years })\end{array}$ & $\begin{array}{l}\text { between grades 3 } \\
\text { and } 6(9-11 \text { years })\end{array}$ & $\begin{array}{l}\text { after grade } 6 \\
(\leq 8 \text { years })\end{array}$ \\
\hline $\begin{array}{l}\text { Taiwan } \\
(\mathrm{n}=193)\end{array}$ & 58 & 135 & 98 & 95 & 0 & 57 & 74 & 60 \\
\hline $\begin{array}{l}\text { Mainland } \\
(\mathrm{n}=80)\end{array}$ & 48 & 31 & 0 & 0 & 80 & 24 & 44 & 10 \\
\hline
\end{tabular}

\subsection{Research Context}

The university in mainland China is a research-intensive institution located in the east coast with 120 years of history. It holds a total enrolment of 42,881 undergraduate and graduate students from 31 schools including science, engineering, medical, humanities and social science, and other disciplines. Students admitted to this university scored at a much higher percentile in the nationwide college entrance exam compared to their peers. In 1998, a local policy was issued to promote bilingual education by offering content area courses with both English and mandarin Chinese as medium of instruction. In 2001, a nationwide policy on bilingual courses accelerated the number of bilingual courses in this university. High-quality bilingual classes among areas of chemistry, biology, informatics or technology such as mechanical electronic information, electrical engineering, computer engineering were popular in teaching science undergraduate majors. The university provides incentives to the instructors who have the qualification (i.e., subject knowledge in the field, and English fluency) to teach the bilingual content courses. The local policy also encourages colleges and departments to adopt original textbooks published in English-speaking countries where more cutting-edge researches are being conducted particularly in the field of 
science and technology. The time allocation of English as language of instruction increases as students move along the semester and final exams are available in both languages. The institutional policy also sets a graduation threshold for students to pass College English Test (CET) level 4, the national English exam in China.

The university in Taiwan is known for pharmaceutical research, with approximately 16,000 undergraduate students from 23 departments including pharmacy, cosmetic science, biotechnology, health care administration, environmental engineering, social work, information management, applied foreign languages, and other cross-field disciplines. The university initiated a series of policies to enhance students' English proficiency level, through providing incentives for bilingual instructors and featuring strong training in English language. For example, the Department of Applied Foreign Languages recruits native English speakers to teach English majors, and hosts English story festival or English week to offer more chances to practice speaking English. Also, the foreign language center also invites English-speaking teachers to chat with students during weekly lunch break to encourage students to practice oral English. All students are required to take freshman English class and pass English language proficiency test (TOEIC 550). If students are from Pharmacy and Applied Foreign Languages, they have to reach TOEIC 700 (perfect score is 990). In addition, assignments and examinations must be completed in English. Some other departments also provide English for specific purposes (ESP) courses, such as from pharmacy, hotel \& restaurant management, tourism \& management, recreation and healthcare management departments. These departments adopt English textbooks published in English-speaking countries from the United Kingdom and the United States. Each summer, the university provides 2 study-abroad programs to US and Australia for 18 to 20 days with opportunities to be immersed in English-speaking countries.

\subsection{Instrument}

According to Seliger and Shohamy (1989) "questionnaires are used mostly to collect data on phenomena that are not easily observed, such as attitudes, motivation, and self-concepts" (p. 172). Along the same line, in this current study, we used an instrument that was developed by Gao et al. (2005) to measure self-identity change among Chinese college students who learned English as a foreign language (EFL). The Gao et al. (2005) questionnaire of L2 self-identity change was classified into six sub-scales, including self-confidence, additive bilingualism, subtractive bilingualism, productive change, split change and zero change. In our study, we excluded the subscale of productive bilingualism because the items were not applicable to our research participants. For example, "as my ability of appreciating English literature and art increases, I have become more interested in Chinese literature and art" would not be appropriate as the non-English majors were not required to take any English literature or culture courses, and therefore, might not provide a valid answer to this type of questions. The rest of the 20 items were measured on a 5-points scale: 1 'strongly disagree', 2 'disagree', 3 'neutral', 4 'agree', and 5 'strongly agree'. In addition, participants were asked to provide their standardized English proficiency test (such as CET and TOEFL) scores at the time of data collection.

\subsection{Procedure and Data Analysis}

Participants were recruited on a voluntary basis to complete a paper-based questionnaire, which was in a bilingual version of English and Chinese (simplified Chinese for mainland group and traditional Chinese for Taiwan group). Participants were informed of the general research purpose. In addition, they were notified that their responses were not related to their final grades, and they could withdraw at any time. All responses were kept confidential. To answer Question 1, factor analysis was conducted to examine the dimensionality and the item reliability statistics in reference to the original version of Gao et al. (2005). To address Question 2, descriptive statistics were explored to identify overall change in self-identity. To answer Question 3, univariate analysis of variance (ANOVA) was applied to test the differences among independent variables on the dependent variables of the five subscales in self-identity change.

\section{Results}

\subsection{Exploratory Factor Analysis (Question 1)}

As was mentioned in our critiques to the literature, psychometric properties are not often reported with instruments that measure self-identity. Gao et al. (2005) only presented an overall item reliability of the 25 items, but failed to conduct factor analysis to determine either the underlying unidimensionality of this instrument, or the legitimacy for treating each of the subscales independently. To address such limitation, we performed an exploratory factor analysis on the 20 items in our sample. First, results from KMO and Bartlett's tests showed that our data are reasonable for factor analysis (KMO Adequacy=. 70). Second, the principal component analysis revealed six components that had an eigenvalue greater than 1 (Table 2), accounting for a total of $58.83 \%$ of the variance, which is a fairly significant amount. Third, factor loadings on each of the six components in Table 2 indicated a clear pattern, ranging from .46 to .83. Further inspection of the items within each component identifies close alignment with Gao et al.s original categorization. For example, the same 4 items load on subtractive change (factor 1); the same 4 items load on additive change (factor 4). However, item 3 itself from the original subscale of self-confidence presents a separate factor 6 with a strong factor loading (and with very small loadings on all other five factors, factor loadings $<.21$ ), which needs to be reverse coded ("When I have difficulties in English learning, I begin to doubt my own ability”). A more recent study (Xu and Gao, 2014) indeed revised the original instrument and proposed a separate subscale of negative self-confidence where this item belongs. Because there is only one item in factor 6 , we decided to remove this factor and the single item and retain the five factors for analysis. In addition, although the factor loadings were somewhat low on item 17 ("No matter which language is used for expression, I remain to be myself") and item 8 ("I have an English name in addition to my Chinese name. They are used in different situations”), these coefficients are very close to a common minimum threshold of .3 (Sass and Schmitt, 2010) and were retained within their original subscale.

After the modification based on exploratory factor analysis, internal consistency was examined with an overall Cronbach alpha of .56 based on the 19 items and 5 subscales, and item consistency for each subscale is listed in Table 2. Psychometric assessment exerts stringent underlying assumptions on unidimentionality particularly for 
personality and attitudinal scale items, and requires the presence of a dominant Eigenvalue (Hambleton et al., 1991) which should account for at least $20 \%$ of the total variance (Reckase, 1979). However, an examination of Table 2 suggests that none of the five factors meets such criteria.

Table-2. Eigenvalues and Factor Loadings

\begin{tabular}{|c|c|c|c|c|c|c|c|}
\hline Item & 1 & 2 & Factor 3 & 4 & 5 & 6 & Cronbach alpha \\
\hline$\%$ of Variance & 15.44 & 13.99 & 9.56 & 8.42 & 5.86 & 5.54 & .60 \\
\hline Eigenvalue & 3.09 & 2.8 & 1.92 & 1.69 & 1.17 & 1.11 & \\
\hline Q9 & 0.67 & & & & & & \\
\hline Q10 & 0.73 & & & & & & 0.735 \\
\hline$\widetilde{Q} 11$ & 0.77 & & & & & & \\
\hline Q12 & 0.67 & & & & & & \\
\hline $\mathrm{Q}^{1}$ & & 0.81 & & & & & \\
\hline $\mathrm{Q}^{2}$ & & 0.70 & & & & & \\
\hline $\mathrm{Q}_{4}$ & & 0.68 & & & & & 0.735 \\
\hline Q17 & & & 0.27 & & & & \\
\hline$\widetilde{Q} 18$ & & & 0.65 & & & & \\
\hline Q19 & & & 0.83 & & & & 0.612 \\
\hline $\mathrm{Q}_{20}$ & & & 0.79 & & & & \\
\hline Q13 & & & & 0.62 & & & \\
\hline Q14 & & & & 0.64 & & & \\
\hline Q15 & & & & 0.60 & & & 0.586 \\
\hline Q16 & & & & 0.63 & & & \\
\hline$\widetilde{Q} 5$ & & & & & 0.46 & & \\
\hline Q6 & & & & & 0.46 & & 0.460 \\
\hline $\mathrm{Q}^{7}$ & & & & & 0.74 & & \\
\hline $\mathrm{Q} 8$ & & & & & 0.29 & & \\
\hline Q3 & & & & & & 0.76 & \\
\hline
\end{tabular}

In addition, a correlation matrix in Table 3 shows a small magnitude of correlation among these factors. Although the possibility of multi-dimensionality or a second-order factor of this instrument needs further investigation and is beyond the scope of this study, we decided to analyze each of these five subscales independently.

Table-3. Correlation matrix among five extracted factors in self-identity change

\begin{tabular}{|c|c|c|c|c|c|}
\hline $\mathrm{N}=273$ & Self-confidence & additive & subtractive & Split & Zero \\
\hline Self-confidence & 1 & & & & \\
\hline additive & $0.165^{* *}$ & 1 & & & \\
\hline subtractive & -0.058 & $.308^{*}$ & 1 & & \\
\hline Split & -0.008 & 0.014 & $.265^{*}$ & 1 & \\
\hline Zero & $-0.195^{* *}$ & -0.037 & $-0.168^{*}$ & 0.050 & 1 \\
\hline
\end{tabular}

***orrrlation is signification at the 0.01 level (2-tailed).

\subsection{General Pattern of Self-Identity Change (Question 2)}

General patterns of identity changes through the questionnaire data suggest that self-confidence change was the most prominent among all $(M=4.00, S D=.78)$, followed by zero change $(M=3.41, S D=.83)$ and additive change $(M=3.20, S D=.73)$. The means of these three subscales were greater than the threshold value of 3 between 'changed' and 'unchanged' (corresponding to the choice of neutral) (Gao et al., 2005) suggesting that there is a change in these subscales among the participants. Comparatively speaking, the means for subtractive change $(M=2.12, S D=.80)$ and split change $(M=2.72, S D=.79)$ are low, and below the critical value of 3.

\subsection{Comparison on Self-Identity Change Subscale (Question 3)}

\subsubsection{Self-Confidence Change}

A two-way ANOVA with major (i.e., arts, English, and science) and gender (i.e., male and female) as betweensubject variables was performed. Results indicated significant main effects of (a) gender, $(F[1,271]=3.89 p=.049$, partial eta squared $=.014)$ and $(b)$ major $(F[1,271]=8.14 p<.001$, partial eta squared $=.058)$. Such difference was further reflected by a significant interaction effect between gender and major $(F[1,271]=3.41 p=$. 035), suggesting that Taiwan female English majors ( $M=4.31, S . E .=$. 09) demonstrated a higher self-confidence change than mainland female $(M=3.57, S . E .=.13)$ and male science majors $(M=3.74, S . E .=.11)$ (See Figure 1). Finally, starting point of English learning and self-confidence are not related $(F[2,268]=.045, p=.95)$. 


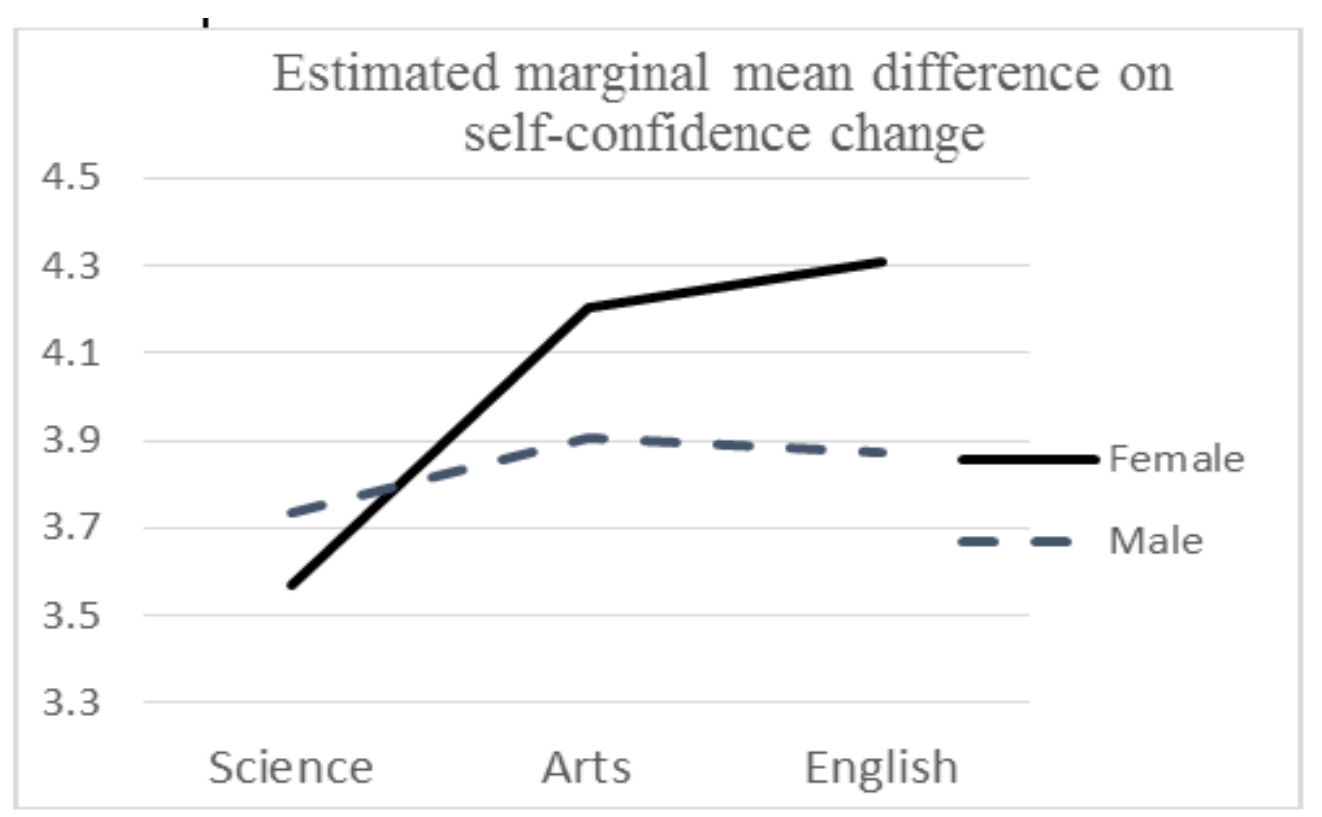

Figure-1. Self-confidence change—-gender by major.

\subsection{Additive Change}

A two-way ANOVA with major (i.e., arts, English, and science) and gender (i.e., male and female) as betweensubject variables was performed. Results indicated a strong and significant main effect of major, $(F[5,271]=25.15$ $p<.001$, partial eta squared $=.159)$. No other main or interaction effects were detected. Post hoc analysis suggested that English majors ( $M=3.611$ S.E.=. 08) demonstrated a statistically higher additive change, followed by bilingual science majors $(M=3.225$ S.E.=. 08) who in turn, scored higher than art majors $(M=2.867$ S.E.=. 072). In addition, although no significance was detected in the two-way ANOVA with major and years of English learning as two between-subject variables on additive change, an examination of Figure 2 implied a within-group difference for the bilingual science majors, which was confirmed by further ANOVA $(F[2,77]=3.428 p=$. 038 , partial eta squared $=.09)$, and Tukey's test: those who started learning English before grade $3(M=3.417$ S.E.=.134) scored significantly higher than late-exposure who started English learning after grade $6(M=2.775$ S.E. $=.208)$.



Figure-2. Additive change by major and starting point of English learning.

\subsection{Subtractive Change}

A two-way ANOVA with major (i.e., arts, English, and science) and gender (i.e., male and female) as betweensubject variables was performed. Results indicated a strong and significant main effect of major, $(F[5,271]=6.94 p$ $=$. 001 , partial eta squared $=.05)$. No other main or interaction effects were detected. Post hoc analysis suggested that both English majors ( $M=2.249$ S.E.=. 089) and bilingual science majors ( $M=2.201$ S.E.=. 089) demonstrated a statistically higher subtractive change than art majors $(M=1.837$ S.E.=. 083, Figure 3). No statistically significant difference was found on subtractive change among years of English learning $(F[2,268]=.394, p=.675)$. 




Figure-3. Subtractive change by major.

\subsection{Split Change}

There is no significant main or interaction effect of gender or major on split change $(F \mathbf{s}<2.778 p s>.069)$, and no statistically significant difference was found among different starting point of English learning $(F[2$, $268]=2.104, p=.124)$.

\subsection{Zero Change}

There is no significant main or interaction effect of gender or major on zero change $(F \mathbf{s}<1.121 p s>.327)$, and no statistically significant difference was found on subtractive change among starting point of English learning $(F[2,268]=.018, p=.982)$.

\section{Discussion}

To iterate, the purpose of this study is to (a) test the psychometric properties of a self-identity change instrument that was previously developed for English-learning college students in China; and (b) applying this instrument, examine participants' self-identity change related to gender, major, and starting point of formal English learning in two adjacent geographic locations (i.e., mainland China and Taiwan). While the exploratory factor analysis suggested an overall adequate alignment with the original instrument developed by Gao et al. (2005) it, however, also supported the deletion of one item that is not psychometrically appropriate, as well as room for improvement on some items with low factor loadings (such as item 8 on additive change, and item 17 on zero change), and low reliability in the subscale of additive change. Although modifications have been made in a recent publication by the original developers (Gao et al., 2005) of the self-identity instrument after the data collection of this current paper, no reliability study has been conducted among its targeted population. Therefore, because of the popularity and scientific grounding of factor analytic procedures on the development and refinement of selfreported psychosocial constructs such as personality and attitudes (Briggs and Cheek, 1986)we recommend that future psychometric research on the underlying construct be conducted with exploratory and confirmatory analysis on instruments that measure self-identity change.

Using the revised instrument with acceptable psychometric indices, we found that overall, college students in our study experienced a change in their self-identity as a result of English learning and bilingual education. More specifically, there is a higher change in the non-cultural change (i.e., self-confidence), and cultural change (i.e., additive and zero) as compared to other changes. Interestingly, such general developments are similar to what was revealed among other groups of Asian college students in mainland China (Gao et al., 2005) Iran (Mokhtarnia and Ghafar-Samar, 2016) South Korea (Vasilopoulos, 2015) and Thailand (Boonchum, 2009). We further discuss our findings on group difference of gender, major, and starting point of English learning on each subscale of identity change.

\subsection{Self-Confidence Change: Mainland China vs. Taiwan}

Passing national and international English proficiency tests increases a candidate's competitiveness and employability in job market, particularly preferred by foreign enterprises that require English proficiency (Pang et al., 2002; Zheng and Cheng, 2008). According to the social identity theory, self-identity is constructed through social contact and experiences (Tajfel, 1974; Dörnyei and Ushioda, 2009). Under the influence of such social surroundings that uphold the value of English proficiency, "it is not a surprise that one's self-confidence is influenced by (perceived) competence in English" (Gao et al., 2015).

We observed an interesting gender difference with female students demonstrating a higher self-confidence change. As Gao et al. (2005) hypothesized, female students might be more sensitive to the learning of English while male students are more 'stubborn' and thus underwent lower level of self-confidence change. In addition, given the fact that a higher confidence change was found (a) among English and art majors (from Taiwan) as compared to bilingual science majors (from mainland China) and (b) among female English majors in Taiwan as compared to male and female bilingual science majors in mainland China, it is worth drawing attention on the subtlety between the two geographic locations that share similar cultural traditions, and yet distinct socio-educational policies and practices concerning college admission and graduation. As one can't ignore the critical nature and influence of testing that prevails the educational arena in Asia, in mainland China students' primary goal to study at primary 
and secondary schools is to succeed in the national college entrance exam (Gaokao), inclusive of English exam, administered only once each year, as the sole key to be admitted to a prestigious institution that promises a brighter future (Davey et al., 2007). However, in Taiwan, there is a multi-channel entrance system that allows applicants multiple attempts if they fail the first set of exams (MOE Taiwan, 2008). It is thus, apparent, that the social experiences of learning English and taking English test before entering college have presented a challenge particularly for students in mainland China, and such pressure doesn't disappear in tertiary education. In fact, although the national policy was eased out in 2005, the practice still prevails as in the majority of college and universities in mainland China, students will not be issued a diploma at graduation if they fail a nationwide standardized English exam (Han et al., 2004). Although in Taiwan there is an equivalent policy the stake is much lower because students can opt from a government-approved list (He and Li, 2009) and the threshold of passing is lower than what is required for graduation in mainland China (Cheng et al., 2014).

Given these educational policies and practices in the two geographic locations, we may explain a lower selfconfidence change in English observed among mainland college students, as compared to their peers in Taiwan where a less grueling college admission and graduation system is implemented, as past experiences in success or failure impacted their confidence in the learning of English. Such finding might be interpreted within socialidentity framework (Spears et al., 2009) that students' self-confidence as one reflection of self-identity was likely to be established throughout their social experiences in tawareness of English learning, the consequence of failing the exam, and the accompanied test anxiety.

\subsection{Additive Change: English vs. Bilingual vs. Non-English Major and Starting Point of Formal English Learning}

Unlike the culture-independent self-confidence change which is associated with the educational policy and practice in the two geographic locations, the culture-dependent additive change is reflected by participants' respective discipline. More specifically, English majors demonstrated the highest additive change, followed by bilingual science majors, who in turn, scored higher than art majors. Similar finding can be found in study with Chinese participants (e.g., Gao et al. (2005)) but stands in contrast with results obtained from other Asian population in Thailand (Boonchum, 2009) and Iran (Mokhtarnia and Ghafar-Samar, 2016). Again, to contextualize the finding, it is important to review English teaching practice in a social-educational community that influences identity formation and integration. As was introduced earlier, English majors in our study were required to take English culture-related courses such as cross-cultural communication and American/British literature, which are also core courses for English majors in other higher institutions in Taiwan (Cheng, 2012). Another prevalent practice, as was evident in the local university in Taiwan, is the recruitment of native English speakers (Wu and Ke, 2009; Wang and Lin, 2013) or graduates from English-speaking countries "who have received or understood American culture and viewpoints in language education" (Liu, 2005) to teach these English majors, which brings them into a new community with target language and culture. From learners' perspective, these English majors chose English as their main area of study, most likely due to their strong English learning motivation, which impacted their identity-change (Xu and Gao, 2014) especially as they continue to familiarize themselves with the target language and culture, and develop into a new disposition and attitudes while maintaining identity of origin.

Although the mainland participants might not have as much exposure and the opportunity to interact with the target group, they were enrolled in a bilingual science course, in which the language of instrument was in both Chinese and English, with a gradual increase in the latter; the instructional materials including the text books were adopted from the original English source (Tong and Shi, 2012). These students expressed a strong and positive attitude toward this bilingual course in promoting their content area knowledge as well as English language proficiency. These students who elected to take this course might be more self-motivated as they held a higher English proficiency (all of them have met the graduation threshold), which could enhance their learning behavior to improve their English deemed critical for content area achievement. Intuitively, art majors in our study underwent the lowest additive change, suggesting a less amount of integration with a dominant identity of origin.

Another interesting finding within the bilingual group revolves around the topic of age of L2 acquisition that has been extensively examined among learners in English-speaking countries (see (Krashen et al., 1979; Cummins, 1981; Hakuta et al., 2000; Irby et al., 2010)). This critical period (aka early sensitivity) hypothesis proposes that given the same amount of exposure and other situational contexts, early starters eventually achieve higher L2 proficiency and bilingualism than adult learners. Such interplay among age, rate of acquisition, and exposure to L2 in EFL settings has been supported by research among EFL learners (Fitzgerald et al., 2015). Similarly, the early start advantage was also reflected in our finding among students who started learning English prior to grade 3 (equivalent to age 8, with 12 or more years of English learning at the time of study) and tended to switch easily between the original and target identities that are integrated. To the opposite, those who started English learning after grade 6 remained unchanged in additive identity, suggesting the dominance of the original identity even though they participated in the bilingual course. This finding bears policy implications as when to offer English curriculum so as to promote additive bilingualism in the long run.

\subsection{Subtractive Change: English and Bilingual Science Major vs. Non-English Major}

In another culture-dependent subtractive identity, the change is lower than what was observed in selfconfidence and additive-change. According to Amiot et al. (2007) model of cognitive-development in identity integration, subtractive identity change occurs when increased integration with a new cultural identity result in a decrease in identification with one's original cultural group. However, the experience of cultural conflicts is not necessarily negative as subtractive change is a developmental phase of the integration process due to a limited depth of linguistic and cultural learning, which can develop into additive self-identity (Gao et al., 2005).

Another reason for little change observed in subtractive identity might be related to the educational practice in the two geographic locations in our study. Although language loss has been reported among immigrants in the United States (Hakuta and D'Andrea, 1992; Valdés, 2004) with a societal and familial pressure to acquire English at a young age, and to replace the minority language, such a subtractive bilingual environment might not be 
applicable in the Chinese landscape where the learning of English is highly desired, but not at a loss of Chinese, which is the majority language.

Nevertheless, there is still significant dissonance among different majors in this study. It is evident that students with more exposure to English (i.e., English major and science major taking bilingual course) underwent more change in subtractive bilingualism. They might be more "westernized" and reject certain aspects of the native culture; in other words, they were developing L2 identity at the expense of reducing the original identity. The finding is in line with what has been reported among Thai college students (Boonchum, 2009). This difference among the different majors can be explained by the positive relationship between instrumental/cultural motivation (such as going abroad) and subtractive identity change (Xu and Gao, 2014). English majors have been reported to exhibit a strong interest in studying or traveling in English-speaking countries (Kitjaroonchai and Kitjaroonchai, 2012) and the learning of English language and the accompanied culture increases the students' curiosity and preference of the new culture by visiting these countries ( $\mathrm{Gu}, 2012)$ and are also encouraged to do so (Li, 2004).

\subsection{Split Change}

Overall, split change was not evident among the participants in our study. Similar to subtractive identity change, the split change is also a process where an individual is introduced to a new cultural and identity, but the new identity is not integrated into the original identity, and thus the individual may still feel fragmented (Amiot et al., 2007; De la Sablonnière et al., 2016) however given more exposure to the target language and culture, such a process may evolve and eventually a more integrated additive identity will emerge.

\section{Conclusion, Limitation, and Recommendation for Future Research}

The learning of a second language may impact the way we think, and how people perceive us, which in turn will change our behavior so as to 'confirm others' expectation. Second language learners' identity goes beyond the language and can be in multiple dimensions such as gender, social class, ethnicity, and network (Baker, 2011). Gardner (1985) socio-educational model suggested that formal and informal language learning can improve foreign language efficiency towards bilingualism. Alongside this learning process, an individual achieves both linguistic and non-linguistic outcomes. For example, the culture of the target language may lead to changes in learners' identity. Although this study is among the few that addresses English learners' self-identity change in expanding circles and explores group differences with policy and practice support, there are several limitations. First, given the sampling strategy, external validity of this study is limited as participants from two universities might not fully represent the population of tertiary students in the two geographic locations, and therefore, we offer possible explanations and presuppositions, rather than making affirmative statements, especially when interpreting differences between the two locations. Second, due to limited access to participants, qualitative data were not obtained through focus group or interview, which could have enriched the findings from learners' perspective. Along the same line, we were not able to include participants' other information such as family social economic status, informal learning, and social networking which constitute multiple layers of bilingualism (Baker, 2011).

Despite the above limitations, this study has the following contributions and recommendations to the field of L2 identity. First, there is a shortage of empirical scholarship on identity change among learners in the expanding circle countries, where the boundary between ESL and EFL is becoming loose, and therefore, research is much desired to avoid "harmful generalizations" (Kumaravadivelu, 2005). Such journey of inquiry should begin with the search for a collection of reliable and valid measures that captures this underlying construct. Second, as Block (2007) argued, even within the EFL contexts there are extreme variations in terms of policy and practices on English language teaching. His observation was echoed by one of our main findings that calls for more studies that take into consideration of comparing geographic locations that share similar or dissimilar socio-cultural or educational characteristics which may impact the identity construction and shift. In addition, major and years of English exposure for bilingual majors both significantly impacted identity integration. The examination of the internal domain of self and identity has important implications for language teachers on how to engage the motivation, interests and identities of language learners (Ushioda, 2011) for them to achieve a harmony between actual self and ideal self, as proposed by Dörnyei (2005) and an additive bilingualism as the ultimate goal of a strong form of bilingual education and bilingualism (Baker and Wright, 2017). Finally, as the development model of social identity integration proposes, identity change is triggered when an individual is introduced into a new community (Amiot et al., 2015) consequently, we recommend future research to target the change in self-identity before and after students are enrolled in a bilingual content area course or their participation in cross-cultural activities and communications.

\section{References}

Amiot, C.E., R. De la Sablonnière, D.J. Terry and J.R. Smith, 2007. Integration of social identities in the self: Toward a cognitivedevelopmental model. Personality and Social Psychology Review, 1 (4): 364-388. View at Google Scholar | View at Publisher

Amiot, C.E., R. Sablonniere, L.G. Smith and J.R. Smith, 2015. Capturing changes in social identities over time and how they become part of the self concept. Social and Personality Psychology Compass, 9(4): 171-187. View at Google Scholar $\mid$ View at Publisher

Baker, C., 2011. Foundations of bilingual education and bilingualism. New York: Multilingual Matters, 79.

Baker, C. and W.E. Wright, 2017. Foundations of bilingual education and bilingualism. 6th Edn.: Channel View Publications.

Block, D., 2007. Second language identities. London and New York: Continuum.

Boonchum, P., 2009. A study of self-identity changes and correlation of influential factors of Thai students studying english. Educational Research and Reviews, 4(1 1): 535-548. View at Google Scholar

Bosma, H. and E. Kunnen, 2001. Determinants and mechanisms in ego identity development: A review and synthesis. Developmental Review, 2 1(1): 39-66. View at Google Scholar | View at Publisher

Boyd, V.S., P.F. Hunt, J.J. Kandell and M.S. Lucas, 2003. Relationship between identity processing style and academic success in undergraduate students. Journal of College Student Development, 44(2): 155-167. View at Google Scholar $\mid$ View at Publisher

Brewer, B.W., 1993. Self-identity and specific vulnerability to depressed mood. Journal of Personality, 61(3): 343-364. View at Google Scholar $\mid$ View at Publisher

Briggs, S.R. and J.M. Cheek, 1986. The role of factor analysis in the development and evaluation of personality scales. Journal of Personality, 54(1): 106-148. View at Google Scholar $\mid$ View at Publisher 
Cheng, L., 2012. The power of english and the power of Asia: English as lingua franca and in bilingual and multilingual educa tion. Journal of Multilingual and Multicultural Development, 33(4): 327-330. View at Google Scholar | View at Publisher

Cheng, L., D. Klinger, J. Fox, C. Doe, Y. Jin and J. Wu, 2014. Motivation and test anxiety in test performance across three testing contexts: The CAEL, CET, and GEPT. TESOL Quarterly, 48(2): 300-330. View at Google Scholar $\mid$ View at Publisher

Clément, R., Z. Dörnyei and K.A. Noels, 1994. Motivation, self-confidence, and group cohesion in the foreign language classroom. Language learning, 44(3): 4117-448. View at Google Scholar | View at Publisher

Crystal, D., 2003. English as a global language. 2nd Edn., Cambridge, UK: Cambridge University Press.

Cummins, J., 1981. Age on arrival and immigrant second language learning in Canada. Applied linguistics, 2: 132-149. View at Google Scholar

Davey, G., C. De Lian and L. Higgins, 2007. The university entrance examination system in China. Journal of Further and Higher Education, 31(4): 385-396. View at Google Scholar | View at Publisher

De la Sablonnière, R., C.E. Amiot, D. Cárdenas, N. Sadykova, G.L. Gorborukova and M.E. Huberdeau, 2016. Testing the subtractive pattern of cultural identification. European Journal of Social Psychology: 441-454. View at Google Scholar | View at Publisher

Dörnyei, Z., 2005. The psychology of the language learner. Mahwah, NJ: Lawrence Erlbaum Associates.

Dörnyei, Z. and E. Ushioda, 2009. Motivation, language identity and the L2 self. New York: Multilingual Matters, 36.

Ellemers, N., R. Spears and B. Doosje, 2002. Self and social identity. Annual Review of Psychology, 53(1): 161-186. View at Google Scholar

Erikson, E., 1968. Identity: Youth and crisis. New York: Norton.

Fitzgerald, J., A.J. Stenner, E.E. Sanford-Moore, H. Koons, K. Bowen and K.H. Kim, 2015. The relationship of Korean students' age and years of english-as-a-foreign-language exposure with english-reading ability: A cross-age study. Reading Psychology, 36(2): 173202 .

Gallagher-Brett, A., 2005. Seven hundred reasons for studying languages. Higher Education Academy. Retrieved from https://www.llas.ac.uk/sites/default/files/nodes/6063/700_reasons.pdf.

Gao, Y., Y. Cheng, Y. Zhao and Y. Zhou, 2005. Self-identity changes and english learning among Chinese undergraduates. World Englishes, 24(1): 39-51. View at Google Scholar $\mid$ View at Publisher

Gao, Y., Z. Jia and Y. Zhou, 2015. EFL learning and identity development: A longitudinal study in 5 universities in China. Journal of Language, Identity \& Education, 14(3): 137-158. View at Google Scholar $\mid$ View at Publisher

Gao, Y., Y. Zhao and Y. Cheng, 2007. Relationship between english learning motivation types and self-identity changes among Chinese students. TESOL Quarterly, 41(1): 133-155. View at Google Scholar | View at Publisher

Gardner, R.C., 1985. Social psychology and second language learning: The role of attitudes and motivation. London, UK: Edward Arnold.

Garrott, R.A., 1995. Effective management of free-ranging ungulate populations using contraception. Wildlife Society Bulletin 1973-2006, 23(3): 445-452. View at Google Scholar

Giddens, A., 1991. Modernity and self-identity: Self and society in the late modern age. Stanford, CA: Stanford University Press.

Gu, F., 2012. Daxue yingyu zhuanye ernianji jieduan yingyu xuexi dongji de fazhan. Inner Mongolia Agricultural University Nature and Science Newspaper, 14(1): 143-144.

Hakuta, K., Y.G. Butler and D. Witt, 2000. How long does it take english learners to attain proficiency? Retrieved from http://repositories.cdlib.org/cgi/viewcontent.cgi? article=1001\&context=lmri.

Hakuta, K. and D. D'Andrea, 1992. Some properties of bilingual maintenance and loss in Mexican background high-school students. Applied Linguistics, 13(1): 72-99. View at Google Scholar | View at Publisher

Hambleton, R.K., H. Swaminathan and H.J. Rogers, 1991. Fundamentals of item response theory. Newbury Park, CA: Sage.

Han, B., M. Dai and L. Yang, 2004. Problems with college english test as emerged from a survey. Foreign Languages and their Teaching, 179(2): 17-23. View at Google Scholar

Hay, I. and A.F. Ashman, 2003. The development of adolescents' emotional stability and general self-concept: The interplay of parents, peers, and gender. International Journal of Disability, Development and Education, 50(1): 77-91. View at Google Scholar |View at Publisher

He, D. and D. Li, 2009. Language attitudes and linguistic features in the China english debate. World Englishes, 28(1): 70-89. View at Google Scholar | View at Publisher

Huang, L., S.W. Chen and C.L. Chien, 2015. The effect of university ranking on learning satisfaction: Social identities and self-identity as the suppressor and mediators. Asian Journal of Social Psychology, 18(1): 33-42. View at Google Scholar

Hwang, Y., 2010. Investigating the role of identity and gender in technology mediated learning. Behaviour \& Information Technology, 29(3): 305-3 19. View at Google Scholar | View at Publisher

Irby, B.J., F. Tong, R. Lara-Alecio, G.P. Mathes, S. Acosta and C. Guerrero, 2010. Quality of instruction, language of instruction, and Spanish-speaking english learners' performance on a state high-stakes reading assessment. TABE Journal, 12(1): 1-42. View at Google

Scholar
Irby, B.J., F. Tong, M. Nichter, R. Lara-Alecio, F. Hassey and C. Guerrero, 2011. Hispanic english learners' self esteem related to instructional program type, language of instruction, and gender. TABE Journal, 3(1): 26-48. View at Google Scholar

Jensen, L.A., J.J. Arnett and J. McKenzie, 2011. Globalization and cultural identity. In handbook of identity theory and research. New York: Springer. pp: 285-301.

Jiang, P., K. Ding and J. Leng, 2016. Towards a cyber-physical-social-connected and service-oriented manufacturing paradigm: Social manufacturing. Manufacturing Letters, 7: 15-2 1. View at Google Scholar $\mid$ View at Publisher

Johnson, J.S. and E.L. Newport, 1989. Critical period effects in second language learning: The influence of maturational state on the acquisition of english as a second language. Cognitive Psychology, 21(1): 60-99. View at Google Scholar | View at Publisher

Kachru, B.B., 1985. The bilinguals' creativity. Annual Review of Applied Linguistics, 6: 20-33. View at Google Scholar $\mid$ View at Publisher

Kai, H. and H. Shin, 2015. The correlation between changes in identity and active learning during the freshman year of university studies. Japanese Journal of Developmental Psychology, 26(2): 98-106. View at Google Scholar

Karakitapoglu-Aygün, Z., 2004. Self, identity, and emotional well-being among Turkish university students. Journal of Psychology, 138(5): 457-478. View at Google Scholar | View at Publisher

Kitjaroonchai, N. and T. Kitjaroonchai, 2012. Motivation toward english language learning of Thai students majoring in english at Asiapacific international university. Catalyst, 7(1): 21-40. View at Google Scholar

Krashen, S.D., M.A. Long and R.C. Scarcella, 1979. Age, rate and eventual attainment in second language acquisition. TESOL Quarterly, 9: 573-582. View at Google Scholar | View at Publisher

Kumaravadivelu, B., 2005. TESOL, globalization, and the empire: A dangerous liaison. Relocating TESOL in the age of Empire: 1-32. View at Google Scholar

Lambert, W.E., 1974. A Canadian experiment in the development of bilingual competence. Canadian Modern Language Review, $31(2):$ 108116. View at Google Scholar

Lasagabaster, D., 2013. Attitudes and motivation in bilingual education. Encyclopedia of Applied Linguistics: 276-281.

Li, X., 2004. A study by the Chinese academy of sciences on the benefits of study abroad. Chinese Education and Society, 37(2): 61-87. View at

Google Scholar
Liu, G., 2005. The trend and challenge for teaching EFL at Taiwanese universities. RELC Journal, 36(2): 21 1-22 1. View at Google Scholar $\mid$ View at Publisher

Matsumoto, M. and Y. Obana, 2001. Motivational factors and persistence in learning Japanese as a foreign language. New Zealand Journal of Asian Studies, 3(1): 59-86. View at Google Scholar

Ministry of Education of Taiwan, 2008. Guidelines in offering english classes in primary and middle schools. Retrieved from http://www.k12ea.gov.tw/97_sid17/英語 970526 定稿單冊.doc.

Ministry of Education of the People's Republic of China, 2001. Suggestions to promote english classes in primary schools in China. Available from http://www.moe.gov.cn/srcsite/A26/s7054/200101/t20010120_166075.html.

MOE Taiwan, 2008. Guidelines in offering english classes in primary and middle schools. Retrieved from http://www.k12ea.gov.tw/97_sid17/英語 970526 定稿單冊.doc.

Mokhtarnia, S. and R. Ghafar-Samar, 2016. An analysis of the relationship between the attitudes of Iranian EFL learners to native english speakers and their reported identity change. Journal of Multilingual and Multicultural Development, 37(6): 589-600. View at Google Scholar 
Noels, K.A., G. Pon and R. Clément, 1996. Language, identity, and adjustment the role of linguistic self-confidence in the acculturation process. Journal of Language and Social Psychology, 15(3): 246-264. View at Google Scholar | View at Publisher

Norton, B., 2006. Second language identity. Oxford: Elsevier.

Norton, B. and K. Toohey, 2011. Identity, language learning, and social change. Language Teaching, 44(4): 412-446. View at Google Scholar $\mid$ View at Publisher

Oliver, M., 2013. The social model of disability: Thirty years on. Disability \& Society, 28(7): 1024-1026. View at Google Scholar $\mid$ View at Publisher

Pang, J., X. Zhou and Z. Fu, 2002. English for international trade: China enters the WTO. World Englishes, 21(2): 201-216. View at Google Scholar |View at Publisher

Papacharissi, Z., 2010. A networked self: Identity, community, and culture on social network sites. New York: Routledge.

Park, H., 2007. English medium instruction and content learning. English Language and Linguistics, 23: 257-274. View at Google Scholar $\mid$ View at Publisher

Qu, W.G., 2005. On issues concerning english and identity research in China. Journal of Chinese Sociolinguistics, 5: 93-116. View at Google

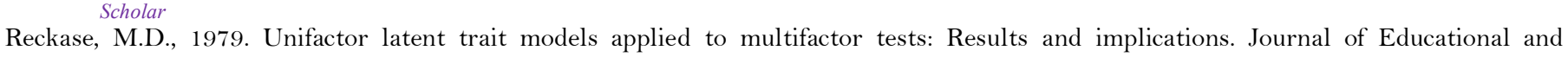
Behavioral Statistics, 4(3). View at Google Scholar | View at Publisher

Risager, K., 2006. Language and culture: Global flows and local complexity. Clevedon, England: Multilingual Matters.

Sass, D.A. and T.A. Schmitt, 2010. A comparative investigation of rotation criteria within exploratory factor analysis. Multivariate Behavioral Research, 45(1): 73-103. View at Google Scholar | View at Publisher

Seliger, H.W. and E. Shohamy, 1989. Second language research methods. Oxford: Oxford University Press.

Sert, N., 2008. The language of instruction dilemma in the Turkish context. System, 36(2): 156-171. View at Google Scholar $\mid$ View at Publisher

Spears, R., N. Ellemers and B. Doosje, 2009. Strength in numbers or less is more? A matter of opinion and a question of taste. Personality and Social Psychology Bulletin, 35(8): 1099-1 111 . View at Google Scholar | View at Publisher

Steele, C.M., 1997. A threat in the air: How stereotypes shape intellectual identity and performance. American Psychologist, 52(6): 613-629. View at Google Scholar | View at Publisher

Sussman, N.M., 2000. The dynamic nature of cultural identity throughout cultural transitions: Why home is not so sweet. Personality and Social Psychology Review, 4(4): 355-373. View at Google Scholar $\mid$ View at Publisher

Tajfel, H., 1974. Social identity and intergroup behaviour. Social Science Information, 13(2): 65-93. View at Google Scholar |View at Publisher

Terry, D.J., M.A. Hogg and K.M. White, 1999. The theory of planned behaviour: Self identity, social identity and group norms. British Journal of Social Psychology, 38(3): 225-244. View at Google Scholar | View at Publisher

Tong, F., 2008. English learning and Chinese cultural orientation. Academic Exchange Quarterly, 12(4): $254-259$.

Tong, F. and Q. Shi, 2012. Chinese-english bilingual education in China: A case study of college science majors. International Journal of Bilingual Education and Bilingualism, 15(2): 165-182. View at Google Scholar |View at Publisher

Tong, F. and S. Tang, 2017. English-medium instruction in Chinese university science classroom: An observation study. In Q. Dixon, J. Zhao, and Y. Sun (Eds.), English-medium instruction in Chinese Universities. Routledge. pp: 128-144.

Tsuneyoshi, R., 2005. Internationalization strategies in Japan: The dilemmas and possibilities of study abroad programs using english. Journal of Research in International Education, 4(1): 65-86. View at Google Scholar $\mid$ View at Publisher

Ushioda, E., 2011. Language learning motivation, self and identity: Current theoretical perspectives. Computer Assisted Language Learning, 24(3): 199-2 10. View at Google Scholar $\mid$ View at Publisher

Valdés, G., 2004. Between support and marginalisation: The development of academic language in linguistic minority children. International Journal of Bilingual Education and Bilingualism, 7(2-3): 102-132. View at Google Scholar | View at Publisher

Vasilopoulos, G., 2015. Language learner investment and identity negotiation in the Korean EFL context. Journal of Language, Identity \& Education, 14(2): 61-79. View at Google Scholar | View at Publisher

Wang, C.M., 2004. Self-concept, english pronunciation and EFL learning. Foreign Language Teaching and Research, 36(1): 56-64. View at

Wang, L.Y. and T.B. Lin, 2013. The representation of professionalism in native english-speaking teachers recruitment policies: A comparative study of Hong Kong, Japan, Korea and Taiwan. English Teaching: Practice and Critique, 13(3): 5-22. View at Google Scholar

Wu, K.H. and C. Ke, 2009. Haunting native speakerism? Students' perceptions toward native speaking english teachers in Taiwan. English Language Teaching, 2(3): 44-52. View at Google Scholar | View at Publisher

$\mathrm{Xu}, \mathrm{H}$. and Y. Gao, 2014. The development of english learning motivation and learners' identities: A structural equation modeling analysis of longitudinal data from Chinese universities. System, 47: 102-115. View at Google Scholar $\mid$ View at Publisher

Zheng, Y. and L. Cheng, 2008. Test review: College english test (CET) in China. Language Testing, 25(3): 408-4117. View at Google Scholar | View at Publisher 